\title{
Las razones de la noche: cine mexicano actual
}

$\frac{\text { ANDRÉS DE LUNA }}{\text { Universidad Autónoma Metropolitana-Xochimilco/México }}$ 


\section{Resumen}

El cine mexicano tiene una historia que comienza con la llegada de los enviados de los Lumiére en 1896. Luego llegó la revolución en 1910 y la cinematografía recuperó la imagen de los caudillos y de las batallas. Una vez que concluye el movimiento armado, se da un cine mudo cargado de evasiones, que imita al cine italiano. En 1936 se forma la industria del cine nacional gracias a la fórmula sugerida por el éxito comercial de Allá en el rancho grande. Después vendrá la época de oro del cine mexicano, llamada así por la gran cantidad de películas que se producían. En los sesenta del siglo pasado sobreviene una crisis que tendrá un reposo más tarde en un cine propositivo cuyos productos fueron de segundo orden. De entonces a la actualidad se ha transitado por un cine cargado de altibajos, sin conseguir una regularidad en sus propuestas y calidades.

\section{Palavras-chave}

cine mexicano, revolución, industria nacional, cine propositivo

\section{Abstract}

The history of Mexican cinematography begins with the arrival of Lumiere's envoys in 1896. The revolution broke in 1910 and Mexican film took the images of its caudillos (military leaders) and its battles. Once the armed movement ended, silent movies were filled with imitations of Italian cinema. In 1936 the national movie industry is inaugurated as such, thanks to a formula that had been suggested by the commercial success of the film Allá en el Rancho Grande. Afterwards, Mexican movies will experience its golden age, in which a great amount of movies were produced. Then, in the sixties, a crisis will arise: during the Presidency of Luis Echeverría, the government, wanting to produce creative and intelligent films, ended up supporting low quality projects. From then on, Mexican cinema has passed through a series of ups and downs, incapable of achieving a consistent quality, both in its aesthetic proposals and its production.

\section{Key words}

Mexican cinematography, revolution, national industry, propositive cinematography 


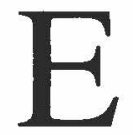

1 cine mexicano sobrevive a muchas circunstancias adversas. Primero fue el kinetoscopio que inventara Edison el que cumplió algunas fantasías de hombres solos, que se apostaban en una calle céntrica, la de san Francisco, para observar con atención las novedades de la imagen en movimiento. Un fragmento favorito del público masculino fue el de la bailarina del vientre, que presentaba a una mujer regordeta capaz de moverse a un ritmo cadencioso. Era el año de 1895. Después vinieron Gabriel Vieyre y Ferdinand Bon Bernard, enviados por los Lumiére para difundir en el mundo las bondades del cine. La sorpresa ante este medio fue mayúscula, y las vistas dieron de que hablar a una sociedad que participaba del juego de las desigualdades. Casi de inmediato se proyectaron las secuencias obtenidas en la República Mexicana, entre ellas Un paseo en el canal de la Viga, Grupo en movimiento del general Díaz y de algunas personas de su familia, El general Díaz paseando a caballo en el Bosque de Chapultepec, El general Díaz en desfile de coches.

Fueron múltiples los fragmentos en los cuales el presidente Díaz es la figura central. Los camarógrafos lo ubican y lo filman con ese aire de prócer que tanto le gustaba. El quiere hacer del cine una maquinaria perfecta de su propaganda personal. Se apela también a un cine historicista,en el cual se proyectan los hechos de forma descriptiva, con la contundencia que pueden tener las imágenes en movimiento. Nadie debe dudar de lo que se hace visible a través de la contundencia fílmica. Tres décadas de dictadura hicieron de Porfirio Díaz una figura que pasó del héroe patrio, del que combatió a los invasores franceses en 1862, para luego sentarse en la silla presidencial sin recordar su origen provinciano y humilde. Ejerció el poder en esos treinta años de construcciones imponentes y miseria 
por doquier. Sólo dejó la presidencia por un periodo corto, un intermedio en el cual gobernó su amigo Manuel González.

Documentales y algunas cintas de ficción marcan la línea de una época que ubica sus comienzos con filmes de orden cómico o cintas que conmemoran hechos patrios, al estilo de 1810: Los libertadores(1916) que recuerda el inicio de la guerra de independencia. Al final el mundo porfiriano se derrumbará ante la inminencia de la Revolución Mexicana (1910-1917). Este fue un movimiento de masas que trataba de implantar un sistema político moderno, que sustituyera al viejo orden, que estaba entrampado en el autoritarismo. La revuelta atrajo lo mismo a hombres tan recios como Francisco Villa; que a campesinos agraristas como Emiliano Zapata, o terratenientes,

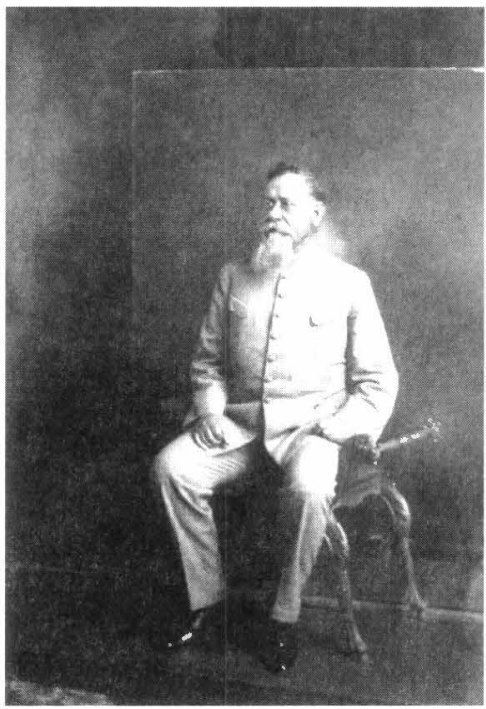
entre los que se encontraba Venustiano Carranza. Por otro lado, el 23 de junio de 1913, se publicó el Reglamento de Cinematógrafos, donde se leían párrafos de humorismo involuntario: hablaba de la protección psiquica y moral a los niños, o la eliminación de las escenas con delitos sin castigo de los culpables, ordenaba a las señoras permanecer sin sombrero durante las exhibiciones; instauraba la censura previa para el material importado; agregaba que habrá un teléfono en cada salón, así como escupideras distribuidas de manera conveniente.

Los cineastas arriesgaron sus vidas al plantarse en los campos de batalla. Entre ellos se recuerda a los hermanos Alva, Salvador Toscano, Ezequiel Carrasco y Jesús H. Abitia. En ese momento el cinematógrafo es vehículo de propagandas caudillistas, la historia la establecerá quien obtenga el triunfo por las armas, y después gracias a las ideas trasladadas en instituciones. De tal modo que el otrora terrateniente Venustiano Carranza se convertirá en el 
Primer Jefe, e impondrá sus manejos políticos al cine, entre ellos el del ordenamiento de la censura en octubre de 1919, esto facilitaba la cisura de aquello que resultaba inapropiado para los intereses del Estado. Al caudillo Zapata se le relegó, pues sus imágenes cinematográficas podían exaltar ciertos ánimos. De manera clara, el Caudillo del Sur, como se le llamaba, fue denostado para evitar que creciera su popularidad, sobre todo, en la capital de la República.

El cine mudo mexicano estableció sus coordenadas entre el culto a las películas italianas de vampiresas, la nostalgia de los terratenientes, así como el uso del filme cargado de lágrimas. Si la ópera italiana tuvo en Metastasio a un inspirador necesario en el fundador del melodrama, en el cine mexicano se dio el caso de filmes que buscaban las realidades de un medio urbano y burgués por medio de la sensiblería. Cine de evasiones, su regularidad consistía en otorgarle a los amores vacuos un lugar en el 'corazón' de hombres y mujeres que se contentaban con repeticiones mal hechas de productos fílmicos europeos.

Un aspecto destacable es la participación femenina, por ejemplo Mimí Derba fue actriz, realizadora, guionista y editora. Entre sus filmes se encuentran En defensa propia (1917), En la sombra (1917), La tigresa (1917), La soñadora (1917). Otros filmes importantes, dentro de la era silente, fueron Obsesión (1917) de Manuel de la Bandera. En la misma época se hizo la primera versión cinematográfica de la novela Santa (1918) de Luis G,
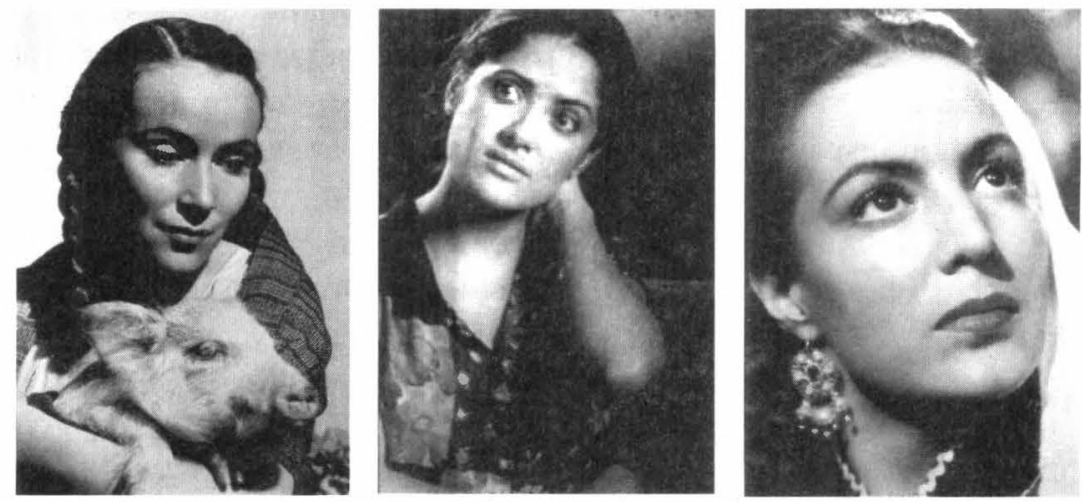

Significaçāo $21 \cdot 33$ 
Peredo. El gran clásico del cine mudo mexicano fue El automóvil gris (1919) de Enrique Rosas y Joaquín Coss, que refiere un hecho de la historia reciente de esa época. En 1915 una banda de falsos militares robó en casas burguesas de la Ciudad de México. Los atracos llamaron la atención y las sospechas recayeron en un posible candidato a la presidencia de la República, un combatiente llamado Pablo González a

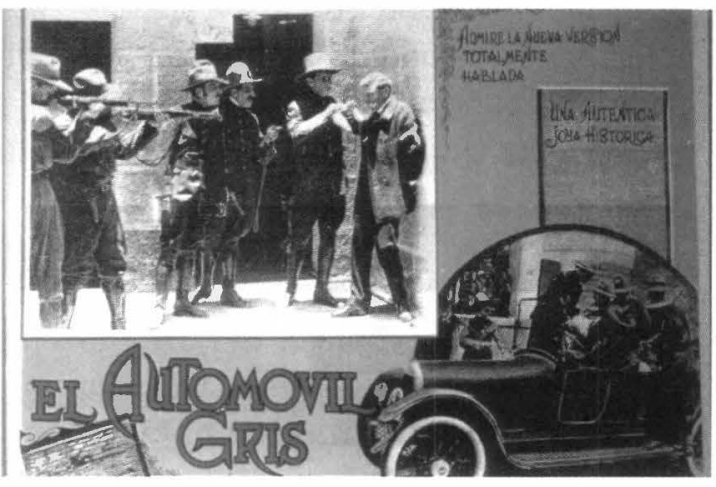
quien la cinta trataba de deslindar de los hechos delictivos. Un ingrediente que atrajo al público fueron las escenas documentales del fusilamiento de algunos integrantes de la banda. La ficción es llamativa pero lo real lo es más. Casi de manera simultánea se filmó La banda del automóvil (1919) de Ernesto Vollrath, que, sin llegar a los logros de la anterior, tocaba el mismo tema.

La etapa sonora llegará en 1931 con Santa de Antonio Moreno, que adaptaba una novela del naturalismo mexicano de Federico Gamboa. El filme era menor y su estructura dramática era precaria. Un hecho importante es la llegada de Sergei Mijailovich Eisenstein a México. Venía de Hollywood y se había caído de la gracia de Stalin. Al país llegó con un proyecto que nunca terminaría: Qué viva México (1931). En él se deslizaron las ideas, anotaciones y visiones folclóricas del cineasta soviético. De pronto era la reminiscencia al mundo prehispánico, con rostros que se comparaban con las figuras mayas; el mundo de la Colonia española con algo de mortecino; sin olvidar las injusticias de la revolución con un episodio que es una pequeña obra maestra, en la cual se remite el director al derecho de pernada, que practicaban los hacendados. Terror y muerte son los elementos dominantes. Mientras que en la realidad presente se hablaba de una corrida de toros, con un episodio que se ha tratado de disolver en las ediciones de la cinta y que Jay Leda en El proyecto 
mexicano de Eisenstein recupera al dejar que sean los rushes, los materiales filmados sin ningún tipo de edición los que hablen. De esa manera, en una pequeña plaza un turista estadunidense traba contacto con un mexicano. La corrida misma tiene un sesgo homosexual. Las tomas así lo indican y Eisenstein lo manifestaba a través de sus dibujos. Incluso se le llevó a la cárcel por sus preferencias eróticas. La película quedó inacabada pero el paso del creador de El acorazado Potiomkim (1925) fue benéfico en algún sentido, proponía una estética y logró atisbos visuales que para bien, en un principio, y para mal, cuando se volvieron lugares comunes. El filme se componía de un prólogo, un epílogo y cuatro episodios: Sandunga, maguey, Fiesta y Soldadera.

Un momento esencial es La mujer del puerto (1933) del cineasta ruso Arcady Boytler, quien hizo su carrera cinematográfica en el país. Con un texto de Guy de Maupassant, el cine mexicano alcanzó un buen grado de depuraciones naturalistas. El tema es el del incesto, asunto difícil en un medio cargado de represiones, sin embargo, Boytler logró hacer un filme cargado de lirismo. En otra tesitura surge la trilogía de la Revolución de Fernando de Fuentes: El prisionero 13 (1933), El compadre Mendoza (1933) y Vámonos con pancho Villa (1935). En la primera cinta, la menos lograda de las tres, un general alcoholizado debe fusilar a su hijo que ha sido

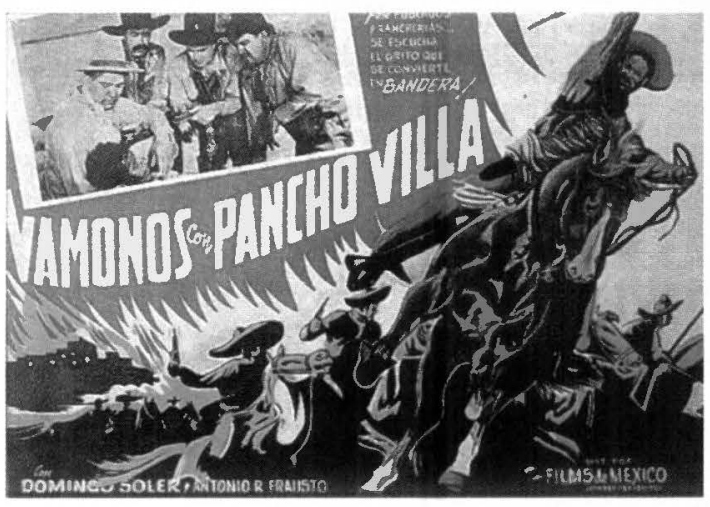
aprehendido. Pero, todo resulta ser un simple sueño etílico. Mientras que en $E l$ compadre Mendoza lo que aparece es el sentido trágico, una densidad dramática irrepetible en la industria fílmica nacional. Con un personaje bonachón, un hacendado que recibe a los revolucionarios con el retrato del caudillo cuyas tripas se presenten ante ese terrateniente. Se le presentan muchas situaciones y con el apotegma 
clásico: Nadie pude servir a muchos dioses, porque acaba por indignarlos a todos. El hombre traiciona a un general zapatista que le ha sido leal, $\tan$ es así que nunca se atreve a insinuar su amor a la joven esposa de Mendoza. Una emboscada termina con la vida del amigo y Mendoza huye de su hacienda con la lluvia tras de sí, con la infamia de la sobrevivencia indigna. Por otro lado, la obra mayor, quien esto escribe se atreve a considerarla la mejor cinta mexicana de todos los tiempos, es Vámonos con pancho Villa (1935), en donde Fernando de

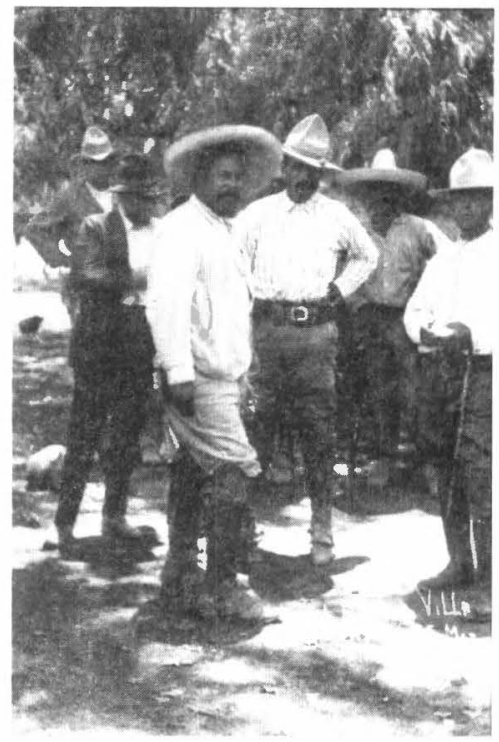
Fuentes narra las falsas expectativas y los mitos que generó el movimiento revolúcionario. Los hombres del pueblo de San Pablo se lanzan a la lucha armada. Ven en Villa a una suerte de Mesías, lo siguen y observan los horrores de la batalla y losa hechos crueles. La cinta se mantuvo con un final que carecía de unos diez minutos, esto debido a la fiereza de las escenas, que los productores consideraron que podían herir la susceptibilidad del público o incurrir en pugnas políticas. Restituido el epílogo, Vámonos con Pancho Villa es la brutalidad absoluta: la esposa y la hija del antiguo soldado villista son asesinadas. El mismo personaje, llamado Tiburcio Maya, cae muerto al apuntar al general Villa, y uno de sus lugartenientes se encarga de acallar la protesta. Lo que sigue es que el hijo, un pequeño sebreviviente, sea trepado al caballo del caudillo revolucionario y se lo lleve al grito que da nombre a la película.

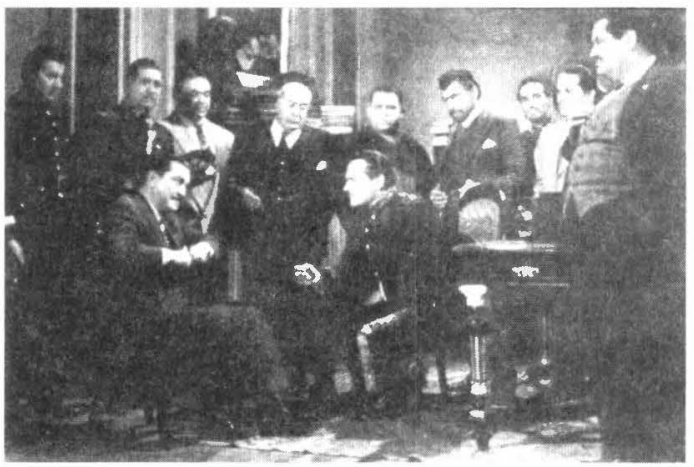


Fue hasta cinco años después que se encontraría la fórmula adecuada para el nacimiento de la industria fílmica, es decir llegaba la comedia ranchera con Allá en el rancho grande(1936) de Fernando de Fuentes, que ganaría un premio por fotografía en el Festival de Venecia.

Después de la Segunda Guerra Mundial los mercados del cine mexicano se vieron favorecidos por la situación que predominaba en el mundo. Filmes de 'charros', figura típica emergida de las haciendas y los ranchos, se convierten en referencia. Pedro Infante y Jorge Negrete alcanzaron un saludable primer plano en las páginas de la fama; sin olvidar la presencia de Mario Moreno Cantinflas, o los rostros de María Félix y Dolores del Río.

Al periodo de mediados de los cuarenta y fines de los cincuenta se le ha llamado Época de oro, pues sus alcances de producción son de un promedio de 100 películas por año.

La crisis se da en los años sesenta del siglo XX. Películas de superhéroes enmascarados, al estilo de los luchadores Santo y Blue Demon, o de cómicos mediocres como Viruta y Capulina, Clavillazo y Resortes, lo mismo que cintas de rock and roll, que imitan un cine juvenil estadunidense o los melodramas familiares señalarán el naufragio de una cinematografía.

En el año de 1968 el país toca fondo con la presidencia del fascistoide Gustavo Díaz Ordaz, quien impone el terror de las armas y propicia matanzas de estudiantes y civiles, las cárceles se repletan de presos políticos y su infamia se refleja en otros órdenes de la cultura. Al llegar a la silla presidencial Luis Echeverría considera que lo mejor es la política de apertura democrática. Entonces de 1970 a 1976 el paternalismo impera y el Estado quiere reivindicarse de forma demagógica. Por un lado se curan las heridas y por otro se abren nuevas. hermano del presidente Echeverría,

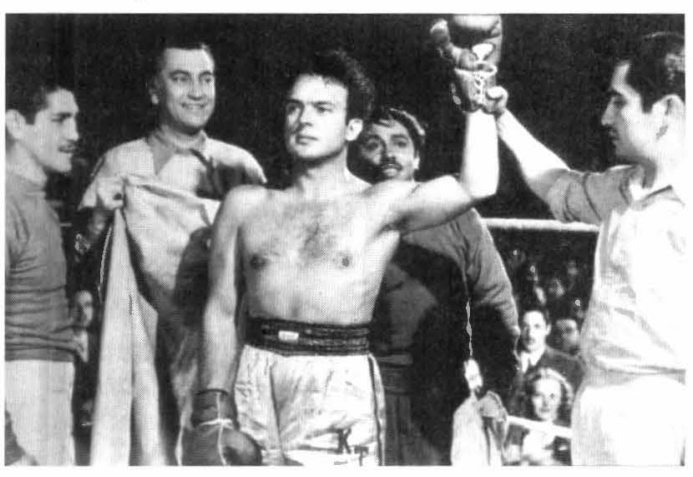



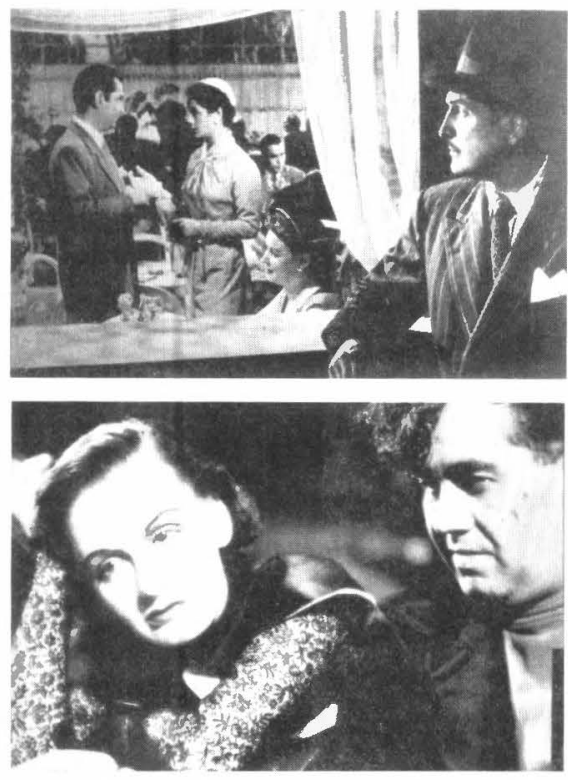

nombre Rodolfo, que era un actor mediano y sin talento, se encarga de las reformas que hacen a un lado a los productores privados, mientras que el Estado quiere, casi por decreto, un nuevo cine nacional. En 1973 el fenómeno corre paralelo a su fracaso inminente. Directores jóvenes ocupan el sitio que antes estaba destinado a los veteranos, la censura permite palabras altisonantes y desnudos integrales, todo con el objeto de crear un público más abierto. Sin embargo, el revés lo da Bellas de noche (1976), filme que inicia un tópico de cabareteras. Esa película se convierte en la película más taquillera de ese periodo presidencial. La diferencia radicaba en que un cine comercial, carente de los mínimos valores, producido con los medios de la producción privada de la que había renegado el presidente Echeverría, de pronto y sin más demostraba su eficacia en términos de gusto de un espectador exento de sentido crítico. El cine hecho con dinero del Estado se convirtió en un elefante blanco, pues se contentó con el paternalismo sin apelar a la indispensable calidad cinematográfica. Es decir Bellas de noche fue un filme ínfimo que puso en su lugar a un cine pretencioso.

Dos sexenios pasan sin que el cine mexicano logre salir de su agonía. El esquema prostibulario llena las pantallas. El cabaret y el burdel son las instituciones y algunos de los peores cineastas filman sin consideraciones para un público semianalfabeto. Por momentos se hacen versiones dobles, una sin censura para consumo de los mexicanos que habitan en la línea fronteriza de Estados Unidos, y otras con los cortes que permiten su exhibición en el país. El resultado es catastrófico. 
En 1988 la política y con ella la nación mexicana están al borde del precipicio: el Partido Revolucionario Institucional comete un monstruoso fraude electoral que impide que el candidato de la oposición llegue al poder. Esto origina una severa crisis. Tan es así que para 1990, se reconsidera el papel de la censura. Esto porque la directora de Cinematografía, oficina encargada de la supervisión, una censura enmascarada, desea prohibir la exhibición de Rojo amanecer (1989) de Jorge Fons. La cinta es un melodrama insignificante que toca de manera lateral los hechos

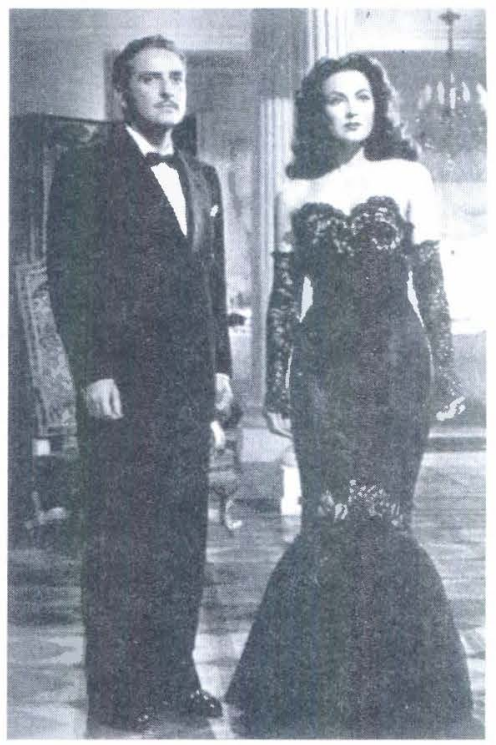
trágicos de la matanza del 2 de octubre de 1968, cuando el ejército dispara contra estudiantes y civiles. También se recupera una cinta secuestrada por los militares de alto rango en 1960: La sombra del caudillo (1959), que refería otro hecho luctuoso: la masacre de Huitzilac, en donde un comando del ejército asesina a un candidato presidencial en 1927. El filme se proyecta en la República y el proyecto neoliberal parece constituirse. El presidente usurpador, Carlos Salinas de Gortari mejora su deteriorada imagen, aunque el cine en general lo deje sin mayores atributos.

Ya en 1994, con una economía en quiebra y con un presidente que ha llegado al poder luego de un atentado mortal al candidato oficial; Ernesto Zedillo fue un tecnócrata que creía en la fuerza de su escritorio y de sus teorías aprendidas en Estados Unidos. El cine se volvió una actividad raquítica, con bajos presupuestos y con cineastas que carecían de una actividad continuada. Por ello, cineastas de calidad regular cobran presencia, tal es el caso de Gabriel retes con El bulto (1991) y Bienvenido/ Welcome (1994).

Mientras que Arturo Ripstein se convierte en el realizador oficial, con un cine esperpéntico y enrarecido. De él todavía se 
recuerdan sus cintas mayores El lugar sin límites (1977) y Cadena perpetua (1978).

En los últimos tiempos se ha podido ver un avance en los contenidos del cine mexicano. Por ejemplo, un filme llamativo es Amo-

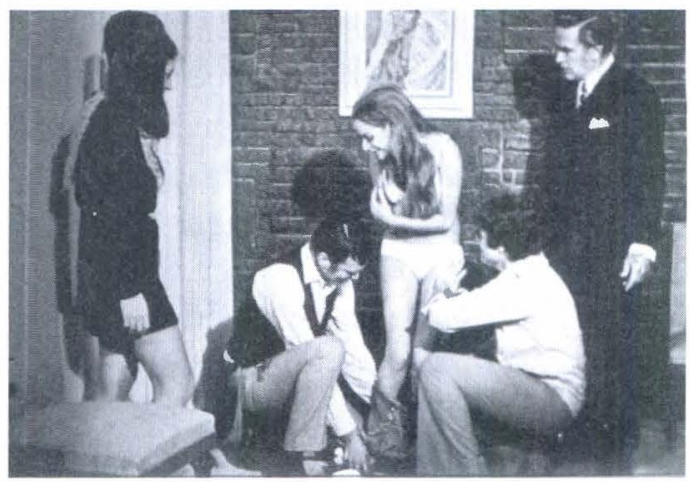
res perros (2001) de González Iñárritu, un hombre que llegó de la publicidad y que concretó una película concebida en forma de relato triple, en el cual de pronto se unían las historias. El primer cuento sobre una pareja an conflicto era un trabajo de indudable mérito. Otra película inportante es Japón (2001) de Carlos Raygadas, un filme semicocumental, con largas secuencias en donde se descubren los beneficios del amor, en un sentido amplio del término, entre un hombre que vive en el desencanto de su realidad y que afloran sus sentimientos en un medio rural empobrecido. Una película que le debe mucr o al trabajo de cineastas como Kauristami

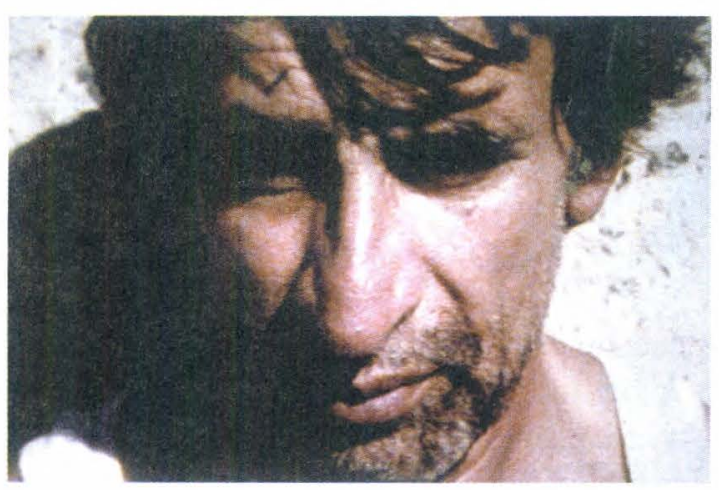
y Tarkovski.

Perfume de violetas (2001) de Marisse Sistach es un filme que describe la vida en una zona paupérrima de la ciudad, en donde el abuso a las adolescentes está a la orden del día. Dos amigas son el punto de zontacto con una realidad atroz. Una de ellas es violada por su termanastro y por un chofer de un transporte urbano. El sufrim ento y 1 amargura dan tono a una cinta espléndida que denuncia las laceraciones de una sociedad que zozobra en la misoginia. 


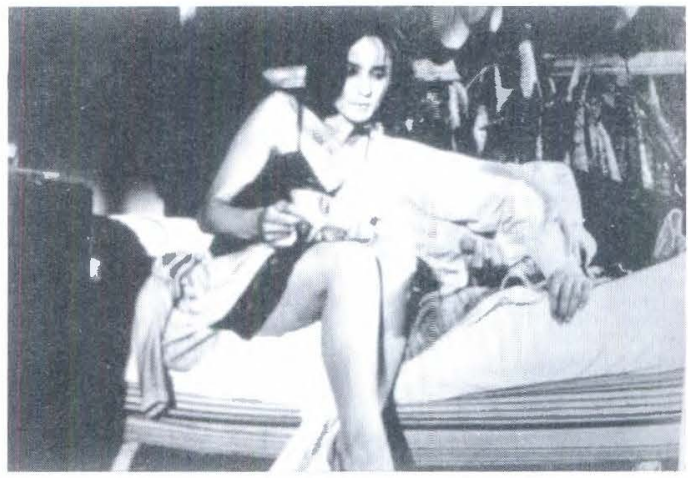

Si Amores perros y Perfume de violetas son aproximaciones a un universo urbano en los tiempos de hoy, El tigre de Santa Julia (2002) de Alejandro Gamboa asume la estética del comic, con paisajes irreales, personaje construidos sin solidez dramática y con más entusiasmo que calidad. La cinta narra las venturas y desventuras de un ladrón generoso que robaba al rico y daba al pobre, la leyenda dice que lo atraparon mientras defecaba en un llano de la zona que habitaba.

En De la calle (2002) de Tort se preocuparon por el aspecto visual, que sugiere un universo que se hace invisible para la mayoría de los habitantes de la capital de la República. Esto se transmite a la población lumpen que llena las calles, las alcantarillas y todo sitio que pueda convertirse en refugio. Un esfuerzo digno.

Vivir mata (2002) de Nicolás Echeverría es una cinta decadente. Unos cuarentones se complacen en el

\section{De la Calle}

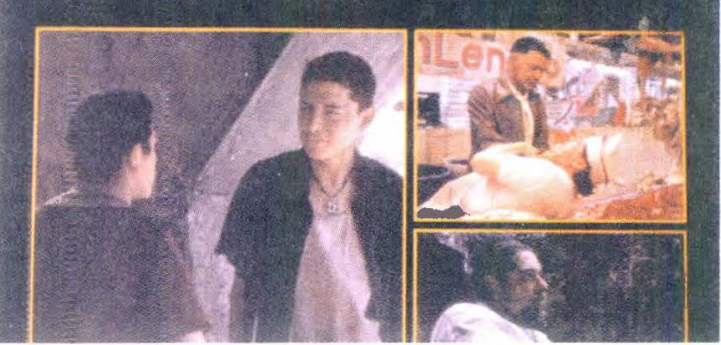

uso de la mentira para atrapar a su compañero de amores. La ciudad se despliega ante el ojo de la cámara, esto con todo y un uso que se pretende surrealista: los avestruces aparecen en escena y cruzan la calle. Echeverría se pierde en una película simplona que desde el guión auguraba poco. 
Por último, habría que mencionar Amar te duele (2002) de Fernando Sariñana, que parte de una idea muy sencilla: observar a sus personaje: bajo la óptica de Romeo y Julieta en los tiempos de la posmodernidad. El realizador emplea toda clase de recursos visuales para hacer más atractiva una historia que se ha contado una y mil veces. Lo mejor es que Amar te duele es una reflexión acerca de una zona de la ciudad que está dividida, por un lado la parte proletaria con jóvenes castigados por el resentimiento social;

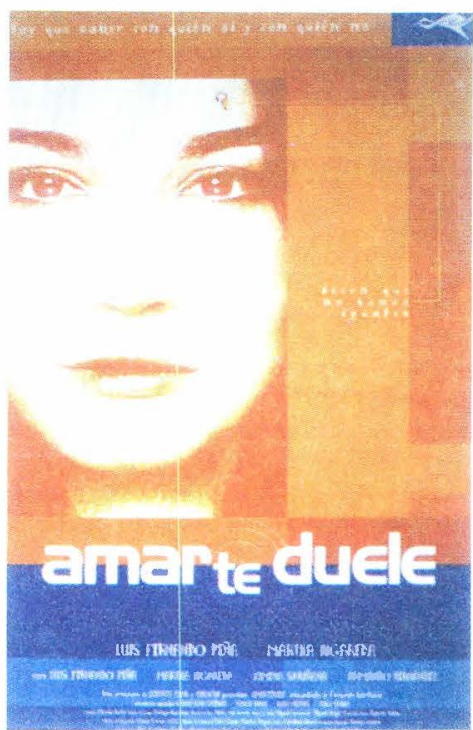
mientras que la parte nueva está habitada por nuevos ricos y centros comerciales que dan un aspecto de ciencia ficción a lo que antes eran minas de arena.

El cine mexicano actual está afectado por el virus de la estética light, una forma de complacencia que dice poco de las realidades de un país aquejado por las corruptelas y el abandono, que es víctima de la delincuencia organizada y el narcotráfico, que tiene a un presidente, Vicente Fox, que ha demostrado sus incapacidades y su falta de entendimiento frente a la cultura. Por todo ello, la cinematografía fluye a cuentagotas, sin los apoyos indispensables y con la incertidumbre de la carencia de recursos y de proyectos. 